de poils ou d'épines, souvent d'une saveur àcre et nauséabonde, ou bien contenant une matière résineuse. Il s'ensuit que les animaux, même très affamés, ne peuvent s'en accommoder, et dépérissent rapidement. J'ai eu l'occasion d'en faire l'expérience.

Cela explique pourquoi les Fourmis Saübas, ne rencontrant pas, dans ces régions, des feuilles à leur convenance, recherchent si avidement les plantes cultivées et généralement importées, à feuillage tendre et lisse, les fleurs et les légumes, les Orangers, Citronniers, Caféiers, Arbres à Coca, etc.

Les Saübas ne s'attaquent donc, d'habitude, qu'aux végétaux utiles à l'homme; c'est pourquoi elles constituent un véritable fléau pour beaucoup de régions de l'Amérique méridionale et centrale.

Dans la vallée du rio Mixiollo, voisine du rio Huallaga, à l'est du Pérou, j'ai vu de grandes colonies de Fourmis Saübas parcourir sans succès la forêt pendant plusieurs kilomètres, à la recherche de végétaux pouvant ètre utilisés, et finir par escalader le tronc lisse de certains arbres fort élevés pour dépouiller, leur couronne de toutes ses feuilles.

\title{
Sur les Amphicrossus de l'Afrique et description d'une espèce nouvelle [CoL.]
}

\author{
par A. Grouvelle.
}

Amphicrossus insularis, nov. sp. - Oblongus, modice convexus, nitidulus, fulvo-pubescens, piceus, antennis ad basin dilutioribus, elytris ad apicem tenuiter rufo marginatis. Caput dense punctatum. Prothorax transversissimus, capite subtilius punctatus, lateribus longe ciliatis, tenuiter marginatis, vix reflexis. Scutellum dense punctulatum. Elytra paulo longiora quam simul lata, ad apicem subconjunctim subtiuncata, prothorace subtilius punctata; pubescentia pilis paulo longioribus li. neato-dispositis intermixta; lateribus longissime ciliatis, vix perspicue reflexis. - o. Fasciculo acuminato pilorum fulvorum vix juxta suturam et ultra medium elytrorum notatus; margine apicali ultimi segmenti abdominis subsinuato, medio duabus carinulis brevibus instructo. — Long. : 4,̋̈-7 mill.

Oblong, modérément convexe, un peu brillant, couvert d'une pubescence fauve, assez dense, entremèlée sur les élytres de poils un peu plus longs, arqués en arrière, disposés en lignes un peu irrégu- 
lières. Tête densément ponctuée. Prothorax environ deux fois et demie plus large dans sa plus grande largeur que long, fortement et largement échancré en avant, aussi densément, mais plus finement ponctué que la tête; côtés régulièrement arqués, déterminant la plus grande largeur un peu en avant de la base, finement rebordés, à peine relevés et assez longuement frangés de poils fauves, serrés. Écusson subpentagonal, densément ponctué. Élytres un peu plus longs que larges ensemble, presque subtronqués ensemble au sommet, un peu plus finement ponctués que le prothorax; bords latéraux à peine relevés, finement rebordés, longuement frangés de poils fauves.

$\checkmark$ đ. Élytres portant, au delà du milieu, un faisceau de poils fauves, très rapproché de la suture; marge apicale du dernier segment de l'abdomen armée au milieu de deux petits tubercules caréniformes, rapprochés.

San Thomé (collection A. Grouvelle).

A. (= Lobostoma) piceus FAIRM. - Après examen du type de l'auteur, j'ai reconnu que Lobostoma picea FAIrm. (Rev. d'Ent. [1892], p. 90-91) devait être rapporté au genre Amphicrossus Er.; Lobostoma tombe donc en synonymie.

L'exemplaire unique (collection AuBert), sur lequel cette espèce est décrite, est un mâle appartenant au groupe des Amphicrossus dont les mâles sont caractérisés par un faisceau de poils placés sur le disque près de la suture.

Chez l'A. piceus Fairm., ce faisceau se trouve un peu au delà du deuxième tiers de la longueur, à une faible distance de la suture.

Tableau des Amphicrossus de l'Afrique.

1. Élytres à peine plus longs que larges ensemble........ 2.

— Élytres franchement plus longs que larges ensemble..... 4.

2. Disque des élytres plus clair; ponctuation du prothorax assez forte, écartée; fascicule des élytres du mâle placé un peu au delà du milieu de la longueur............

Fairmairei GROUV. Madagascar.

- Élytres concolores; ponctuation du prothorax fine et dense. 3.

3. Frange des élytres très longue; fascicule des élytres du mâle placé sensiblement au milieu de la longueur (1)..

fuscus Murr. Afrique occid.

(1) Nous n'avons pas vu d'exemplaires typiques authentiques de cette espèce. 
- Frange des élytres courte; fascicule des élytres du mâle placé un peu en avant du milieu de la longueur (1)....

4. Brillant; peu densément ponctué sur les élytres; pas de fascicule sur les élytres du mâle.... natalensis Grouv. Natal.

- Peu brillant; densément ponctué sur les élytres, ceux-ci fasciculés chez le mâle...................... ร..

5. Élytres arrondis séparément au sommet; fascicule des élytres du mâle placé vers le dernier quart de la longueur.... $\ldots \ldots \ldots \ldots \ldots \ldots \ldots \ldots \ldots \ldots \ldots \ldots \ldots$ piceus FaIRM. Obock. - Élytres subtronqués au sommet; fascicule des élytres du mâle placé un peu au delà du milieu de la longueur.. insularis Grouv. San Thomé.

\section{Note sur une aberration remarquable de Glytus arvicola Oliv. \& [CoL.]}

par F. Gruardet.

La coloration de cet insecte diffère des autres Clytus arvicola capturés dans la même région, par les $2^{\mathrm{e}}$ et $3^{\mathrm{e}}$ bandes jaunes qui sont très larges.

La bande noire qui les sépare est envahie par le duvet jaune et parait presque interrompue sur le milieu de chaque élytre. La région qui entoure la $\mathbb{1}^{\text {re }}$ bande jaune est plus nette. Sa teinte est analogue à celle des épaules, mais légèrement plus foncée entre les deux bandes jaunes.

Le reste de l'insecte n'offre rien de particulier.

L'insecte a été capturé dans la forêt de Fontainebleau, le $\mathbf{1 6}$ juillet 1906.

(1) Nous n'avons pas vu d'exemplaires typiques authentiques de cette espèce. 


\section{$2 \mathrm{BHL}$ Biodiversity Heritage Library}

1908. "Sur les Amphicrossus de l'Afrique et description d'une espece nouvelle." Bulletin de la Société entomologique de France 1908, 108-110. https://doi.org/10.5962/bhl.part.5607.

View This Item Online: https://www.biodiversitylibrary.org/item/37020

DOI: https://doi.org/10.5962/bhl.part.5607

Permalink: https://www.biodiversitylibrary.org/partpdf/5607

\section{Holding Institution}

Smithsonian Libraries

\section{Sponsored by}

Smithsonian

\section{Copyright \& Reuse}

Copyright Status: NOT_IN_COPYRIGHT

This document was created from content at the Biodiversity Heritage Library, the world's largest open access digital library for biodiversity literature and archives. Visit BHL at https://www.biodiversitylibrary.org. 